\section{Zur Syphilis-Behandlung.}

Vortrag, gehalten im Aerzte-Verein des Reg.-Bezirks Breslau, ain 25. November 1883.

Von

\section{Prof. Dr. A. Neisser in Breslau.}

\section{(Schluss aus No. 1.)}

11. Fragen wir nun weiter, wie zu behandeln ist, so will jch hier nur die wichtigsten Sätze der antisyphilitischen Therapie kurz aufstellen. Wir halten die Schmierkur für die heste Methode der Quecksilber-Allgemeinhehandlung, und zieben sie der Injectionskur wie der Application per os und durch Bäder vor. Die letztgenannten Methoden verwende ich nur, wenn äussere Verbältnisse die Inunctionskur unmöglich machen, oder wenn es sich um zweite, dritte etc. Kuren im Verlaufe längerer Syphilishehandlung handelt. Als Injectionsnittel ist am hesten zu verwenden die Müller-Stern'sche SublimatchlornatriumLösung oder das Quecksilher-Pepton. Das neue von Liehreich empfohlene Formamid zeichnet sich, falls man üher ein gutes Präparat verfügt, durch fast absolute Schmerzlosigkeit aus; ich kann indess heute über seine weiteren Vorzüge oder Nachtheile in Bezug auf den Verlauf der Syphilis Definitives noch nicht mittheilen, da unsere Versuche zwar zablreich, die Beohachtungsfristen aher noch zu kurze sind, um über die Häufigkeit etc. der Recidive ein Urtheil zu gestatten. Zur internen Behandlung verwenden wir am liebsten Suhlimat in kleinen Dosen his 0,02 pro die, am hesten in wässriger Lösung (mit Kochsalz) in reichlichen Mengen Milch, weil wir bei dieser Applicationsweise am wenigsten Magen- und Darmheschwerden beobacbten.

Ungleich hesser wird von vielen Patienten das Hydrargyrum jodatum flavum vertragen; doch ist nicht zu ühersehen, dass dasselhe grösserentheils unresorbirt durch den Darmkanal wieder entleert wird.

Das Jodkalium erscheint als Unterstützungsmittel der Quecksilherbehandlung für die Frühstadien von Werth; als directes Heilmittel gegen die Syphilis betrachten wir es nicht. Es beseitigt mehr die Producte des Syphilisgiftes, als das Virus selbst. Hierdurch wird es für die Spätperiode, also für die gummösen Infiltrate, das Hauptmittel, während das Quecksilher (welches das syphilitische Virus selhst angreift und zu vernichten scheint) in diesem Spätstadium an Bedeutung meistens zurücktritt.

Alle ührigen Medicationen durch Bäder, Brunnen, Holztränke u. s. w. sind in ibrem Nutzen durchaus nicht zu unterschätzen, besitzen aber nur die Bedeutung von Adjuvantien der principalen Quecksilber- (und Jod-) Therapie.

III. Als dritte Frage hatten wir aufgestellt, wie lange ist die Allgemeinheliandlung fortzusetzen? Sie lässt sich leicht für alle diejenigen Fälle beantworten, hei denen Recidive auf Recidive folgen. Hier werden intermittirend in gehörigen Zeitahständen Quecksilher- und auch Jodkalium-Behandlungen einzuleiten sein. Die Dauer der Zwischenzeiten hemisst sich einmal nach der heohachteten Wirkung des Quecksilbers auf den Organismus, nach der Constitution, den Ernährungsverhältnissen etc., andererseits sind sie durch die Erfabrung geboten, welche lehrt, dass das Quecksilher, wenn es eine Zeit lang dem Organismus zugeführt worden ist, seine Wirksamkeit einbüsst, und dass sich die Empfängliclıeit im Organismus wieder herstellt, wenn mit der Verabreichung des Hydrargyrum eine Zeit lang pausirt worden ist. Daraus hat Fournier die Methode der sogenannten, intermittirenden successiven Bebandlung " construirt, d. b. er verordnet auf mindestens $1 \frac{1}{2}-2$ Jahre hindurch eine durch immer grösser werdende Zwischenräume von 4 Wochen, 6 Wochen, 8 Wochen zu unterbrechende Quecksilherbehandlung. Die Pausen füllt er, je nach dem Status und dem Bedürfniss, mit Jodkalium-Verahreichung aus.

Die Frage nach der Dauer der Behandlung ist auch dann eine nicht so schwer zu heantwortende, wenn tertiäre Affectionen sich einstellen. Wir kennen diesen Neubildungen gegenüber das Jodkalium als das souveräne Mittel, und es ist nur binzuzufügen, dass nicht zu kleine Dosen verabreicht werden sollen. Neuerdings ist auch erfahrungsgemäss festgestellt worden, dass das sogenannte combinirte Verfabren, das heisst Inunctionskur plus Jodkalium, speciell überall da von eminentem Werthe ist, wo schwere Erscheinungen seitens des Gebirns und Rückenmarks vorliegen. Nur ist auch hier Fournier's Satz: "Wenig thun ist so gut wie nichts thun", zu heherzigen, und demgemäss Quecksilher wie Jodkalium in reichlicher Quantität zu verahreichen.

Wie aber verbält man sich in den Fällen, in denen einige wenige gutartig verlaufende Frühsymptome vorliegen und nachber eine, vollständige Gesundheit vortäuschende, Zeit ahsoluter Symptomlosigkeit sich einstellt? Ist die Syphilis in diesen Fällen nur latent, so dass sie jeden Augenhlick also wieder zum Vorschein kommen kann, oder ist sie wirklich heseitigt?
Könnten wir diese letztere Frage mit Sicherheit beantworten, so wäre dem Praktiker vollkommen geholfen, wie üherhaupt wobl dạs schwierigste Prohlem der Syphilislehre gelöst. Aher sie kann nicht beantwortet werden, und weder das Feblen noch die Existenz von LymphdrüsenSchwellungen, noch die sogenannten provocatorischen Aetzungen Tarnowsky's, noch die Anwendung der Schwefelbäder hahen irgend welclien Fingerzeig nach dieser Richtung hin geboten. Das Aushleihen syphilitischer Erscheinungen auf solche provocatorische Kuren besitzt nicht die geringste Beweiskraft für die thatsächliche Gesundheit des betreffenden Patienten. Bei dieser Sachlage nun, meine Herren, halte ich es für das Richtigste, solche Individuen nicht als gesund zu betrachten, und trotz feblender Symptome den Anscbauungen Fournier's gemäss a u ch für diese Fälle die intermittirende successive Behandlung auf das strengste durchzuführen. Es ist freilich nicht ganz leiclit, Patienten, die frei von jeglichen Symptomen und Beschwerden sind, immer wieder zu einer Kur zu hewegen; aher ich balte mich für verpflichtet, diese Versuche jedes Mal zu machen, und mache sie überall, wo nicht bestimmte Gründe mir die Anwendung der successiven Quecksilber- und vielleicht Jodkalium-Behandlıng verbieten. Solche Contraindicationen sind die Tuberculose sive scbwere Scrophulose, überhaupt bochgradige Anänie und Kachexie, und ferner das Bestehen jener eigenthümlichen Form von Syphilis, die wir am hesten als galoppirende Syphilis bezeichnen. Es ist dies jene Form, hei der die einzelnen Stadien sich nicht in langsamem, schrittweisen Verlauf an einander schliessen, häufig durch lange Intermissionen getrennt verlaufen, sondern wo in rascher Aufeinanderfolge, im Galopptempo ulceröse Formen schon wenige Wochen und Monate nach der Infection entstehen, häufig verhunden mit einer nicht unheträchtlichen und das Lehen des Patienten oft genug gefährdenden Kachexie. In diesen Fällen ist einzig und a llein roborirendes Verfabren am Platze, höchstens sind nehen demselhen Holztränke und Schwitzkuren indicirt, bis die Resistenz des Organismus nach einigen Monaten sich so gehohen bat, dass nun wieder direct antisyphilitische Maassnahmen zur Anwendung gelangen können. Nichts Verfehlteres gieht es, als bei diesen malignen Formen Quecksilherkur auf Quecksilherkur zu verordnen in dem Wahne, durch die Quantität dieses an sich so werthvollen Mittels den Erfolg 7u erzwingen. Er bängt hier, wie überall, nicht nur von der Beschaffenheit der Krankheit, sondern ebenso von der Individualität des Kranken ab.

Abgesehen von diesen speciell angefülırten Zuständen, glauhe ich für das Gros der Syphilisfälle der Fournier'schen üher Jahre sich erstreckenden intermittirenden Bebandlung am meisten das Wort reden zu sollen. Und es ist nicht nur die Autorität Fournier's und die glänzende Darstellungsweise seiner Doctrin, welche uns besticht, sondern es ist wesentlich die hacterielle Anschauung, welche uns zu eifrigen Anhängern seiner Methode macht.

Ihnen allen ist bekannt jene herühmte Lehre Virchow's über das Zustandekommen der Latenz wie der Recidive in dem langen Verlauf der Syphilis. Seiner Auffassung nach kapsele sich das Gift während der Latenzperioden in den Lymphdrüsen ah, um $\mathrm{zu}$ gewissen Zeiten und unter uns noch nicht klar übersehbaren Bedingungen wieder von Neuem in den Säftestrom einzutreten und so die Recidive berbeizuführen.

Es muss also, da wir namentlich mit Rücksicht auf den Gesammtorganismus nicht im Stande sind, durch eine einmalige Kur das Gift in toto zu vernichten, unsere Aufgahe sein, in verschiedenen Perioden successive die noch restirenden Keime anzugreifen und nach Möglichkeit zu zerstören. Deshalh die Wiederbolung der Que cksilberapplication.

Die Verabreichung des Jodkaliums in den $Z$ wischenpausen ist meist von grossem Nutzen, der in der resorptionshefördernden Wirkung dieses Medicaments auf alle syphilitischen Neubildungen zu suchen ist. Man kann sich vielleicht vorstellen, dass auf diesem Wege sonst gleichsam abgekapselte Krankbeitskeime der Einwirkung des nachtrảglich verordneten Quecksilhers überhaupt erst zugänglich werden.

Selbstverständlich hleiht es immer unsere Aufgabe, hei dem Gehrauch dieser specifischen Mittel das Kräftemaas des Kranken im Auge zu hebalten und dasselhe zur Richtschnur unserer Verordnungen in Bezug auf Diät und allgemeines bygienisches Verbalten zu machen. Eine kräftige und reichliche Nahrung wird neben reichlichem Luftgenuss in den meisten Fällen am Platze sein, und die in früberer Zeit so bäufig misshräuchlich angewendeten Entziehungskuren werden nur selten, böcbstens bei ühernährten, sehr saftreichen Individuen Anwendung finden.

Aher nicht nur für den hisher einzig und allein in's Auge gefassten Krankheitsverlauf scheint die so eben hesprochene Jahrelange Quecksilher- und Jod-Bebandlung empfehlenswerth, sie verdient, wenn ich mich nicht täusche, eine ganz hesondere Berücksichtigung für die Frage der Vererhung. Es ist ja hekannt, dass die Vererhung in den Fällen, die ohne Behandlung sich selhst üherlassen bleihen, gesetzmässig 
mit dem zunehmenden Alter der Erkrankung spontan abnimmt, dass jedoch andererseits unter dem Einfluss einer gut durchgeführten Quecksilberbehandlung diese sonst gesetzmässige Vererbliclıkeit der Krankheit regelmässig unterbrochen wird.

Es ist wohl nun denkbar, dass eine Jahre lang durchgeführte Behandlung diese Vererbungsfähigkeit nicht nur zeitweise zu unterbrechen, sondern auch schneller ganz und gar zu beseitigen im Stande sein wird, als dies ohne alle Behandlung der Fall sein würde oder bei jener Methode erwartet werden kann, welche nur beim Wiederauftreten bedeutsamerer Symptome eine Allgemeinbehandlung einleitet. Für den Grad der Vererbungsfähigkeit bietet - abgesehen von eingeschobenen Quecksilberkuren - weder das Auftreten noch das Ausbleiben von Symptomen einen Maassstab, und es erscheint deshalb eine Behandlungsmethode, welche sich von der Anwesenheit oder Abwesenheit solcher Symptome abhängig nıacht, ganz werthlos. - Die Fournier'sche Therapie gewinnt dadurch für die Frage, wann Inficirte sich verheirathen dürfen, eine besondere Wichtigkeit, dahin gehend, dass hier neben einem zeitlichen Abstand zwischen Infection und Ehe eine ausreichende Behandlung, speciell im Fournier'schen Sinne wird gefordert werden müssen.

Zu erwälınen bleibt noch die von Güntz empfohlene Chromwasserbehandlung! Nach meiner Meinung besitzt sie nicht den Werth, der ihr von dem Erfinder zugeschrieben wird. Die Mittlıeilungen des Autors selbst, speciell die reichlichen Krankengeschichten beweisen zur Evidenz, dass das Ziel der angewendeten und anempfohlenen Behandlung durchaus nicht erreicht ist. 